\title{
1 Landslide risk zoning in Ruijin, Jiangxi, China
}

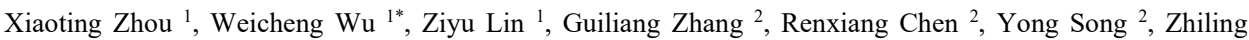 \\ Wang ${ }^{2}$, Tao Lang ${ }^{2}$, Yaozu Qin ${ }^{1}$, Penghui Ou ${ }^{1}$, Wenchao Huangfu ${ }^{1}$, Yang Zhang ${ }^{1}$, Lifeng Xie ${ }^{1}$, Xiaolan \\ Huang ${ }^{1}$, Xiao Fu ${ }^{1}$, Jie Li ${ }^{1}$, Jingheng Jiang ${ }^{1}$, Ming Zhang ${ }^{1}$, Yixuan Liu ${ }^{1}$, Shanling Peng ${ }^{1}$, Chongjian Shao ${ }^{1}$, \\ Yonghui Bai ${ }^{1}$, Xiaofeng Zhang ${ }^{3}$, Xiangtong Liu ${ }^{4}$ and Wenheng Liu ${ }^{1}$ \\ 1 Key Laboratory of Digital Lands and Resources and Faculty of Earth Sciences, East China University of Technology, \\ Nanchang, 330013 Jiangxi, China \\ 2264 Geological Team of Jiangxi Nuclear Industry, Ganzhou, Jiangxi, China \\ 3 School of Geophysics and Measurement-Control Technology, East China University of Technology, Nanchang, 330013 \\ Jiangxi, China \\ ${ }^{4}$ Faculty of Geomatics, East China University of Technology, Nanchang, 330013 Jiangxi, China \\ *Correspondence: Wuwc030903@sina.com/wuwch@ecut.edu.cn; Tel.: +86-18970847278
}

Abstract: Landslides are one of the major geohazards threatening human society. This study was aimed at conducting such a hazard risk prediction and zoning based on an efficient machine learning approach, Random Forest (RF), for Ruijin, Jiangxi, China. Multiple geospatial and geo-environmental data such as land cover, NDVI, landform, rainfall, stratigraphic lithology, proximity to faults, to roads and to rivers, depth of the weathered crust, etc., were utilized in this research. After pre-processing, including digitization, linear feature buffering and value assignment, 19 hazard-causative factors were eventually produced and converted into raster to constitute a 19-band geo-environmental dataset. 155 observed landslides that had truly taken places in the past 10 years were utilized to establish a vector layer. $70 \%$ of the disaster sites (points) were randomly selected to compose a training set (TS) and the remained $30 \%$ to form a validation set (VS). A number of non-risk samples were identified in low slope $\left(<1-3^{\circ}\right)$ areas and also added to the TS and VS in the similar percentage. Then, RF-based classification algorithm was employed to model the probability of landslide occurrence using the above 19-band dataset as predictive variables and TS for training. After performance evaluation, the RF-based model was applied back to the integrated dataset to calculate the probability of the hazard occurrence in the whole study area. The predicted map was evaluated versus both TS and VS and found of high reliability in which the Overall Accuracy (OA) and Kappa Coefficient (KC) are $91.49 \%$ and 0.8299 respectively. In terms of the risk probability, the predicted map was further zoned into different risk grades to constitute landslide risk map. Modeling results also revealed the order of importance of the 19 causative factors, and the most important ones are the proximity to roads, slope, May-July rainfall, NDVI and elevation. We hence conclude that the RF algorithm is able to achieve the risk prediction with high accuracy and reliability, and this study may provide an operational methodology for geohazard risk mapping and assessment. The results of this study can serve as reference for the local authorities in prevention and early warning of landslide hazard.

Keywords: Landslide; Hazard factor quantification; Random Forest; Risk zoning

\section{Introduction}

Landslides are frequent natural disasters, which pose a serious threat to traffic, property and safety of people (Wu and Ai, 1995; Nadim et al., 2006; Assilzadeh et al., 2010; Froude and Petley, 2018). Petley (2012) stated that the damage caused by non-seismic landslides is severe around the 
world, especially in Asia, and we used to underestimate the toll caused by this kind of disaster. Ruijin County in Jiangxi, South China is such an area where landslide calamity constitutes a serious threat and problem to human society. According to the 264-Geological Team (of the Geological Bureau of Jiangxi Nuclear Industry), landslides have caused damage to 104 residential buildings, and made 2319 people homeless in the past decades. Affected by landslide disaster, the construction and use of the newly-built campus of No. 6 Middle School in Ruijin County have been suspended. The uncertainty and suddenness of disaster constitute potential threats to human daily life (Nadim et al., 2006; Froude and Petley, 2018). The recognition of potential landslide-prone areas acts as an essential part in hazard early warning and aiding decision-makers in land use planning and resource management, as well as reducing losses caused by disasters (Aleotti and Chowdhury, 1999; Wu et al., 2016; Arabameri et al., 2020).

In the past decades, a number of studies about landslide risk prediction and assessment have been conducted (Montgomery and Dietrich, 1994; Guzzetti et al., 1999; Aleotti and Chowdhury, 1999; Ayalew and Yamagishi, 2005; Ruffff and Czurda, 2008; Arabameri et al., 2017). These studies have proposed a variety of landslide risk prediction and assessment methods, e.g., knowledge-based, physical, and data-driven methods (Corominas et al., 2014; Reichenbach et al., 2018; Li et al., 2017). Actually, advantages and limitations exist in each approach, for example, knowledge-based and physical methods are mostly intuitive but qualitative or half quantitative (Corominas et al., 2014; Goetz et al., 2015; Li et al., 2017), while data-driven methods are quantitative, yet require powerful computing capacity for big data processing. On the whole, data-driven methods seem more promising for a higher prediction accuracy than other methods, and thus shall be more suitable for landslide risk assessment in areas where there is insufficient geotechnical data (Guzzetti et al., 1999; Corominas et al., 2014; Furlani and Ninfo, 2015; Li et al., 2017; Zhu et al., 2019).

Owing to the heterogeneity in geological and environmental conditions, the scale and mechanism of landslides may differ from one place to another (Cao et al., 2019). This makes the hazard prediction complicated and requires a consideration of the hazard-causative factors as many as possible while dealing with such risk assessment. Recently, remote sensing (RS) and Geographic Information System (GIS) have been taking an significant part in the study of disaster risk zoning (Grizer et al., 2001; Wu et al., 2003; Wang et al., 2005; Lai et al., 2019; Chang et al., 2020). RS technique can provide not only multitemporal and time-series spatial information of large and even inaccessible areas over span of decades but also timely pre- or post-hazard spatial data easily (Youssef et al., 2009; Wasowski et al., 2015; Arabameri et al., 2020). Therefore, RS is an effective tool for hazard monitoring and assessment. To be precise, satellite images can provide the environmental factor layers (e.g., topography, land cover and anthropogenic activities) which can be used for landslide risk prediction and modeling (Pradhan et al., 2010; Arabameri et al., 2020). The other main intrinsic geological and meteorological hazard-inducing factors are also fundamental and essential for this purpose.

In the past years, machine learning techniques including artificial intelligence and deep learning have gained a momentum in geospatial big data processing. For example, data-driven algorithms such as Support Vector Machines (SVM), Random Forests (RF), and Artificial Neural Networks (ANN) have been well applied in land resource mapping (Wu et al., 2016), prediction of soil salinity (Wu et al., 2018) and of ore mineralization in geological field, and shown a superior 
performance to the traditional approaches (Huang, 2018; Qin et al., 2018; Achour and Pourghasemi, 2019; Dou et al., 2019; Sameen et al., 2020). Comparing with other machine learning approaches, the RF algorithm has clear advantages, i.e., it does not require to normalize and discretize the data, and is less sensitive to outliers and runs faster than SVM (Breiman, 2001; Wu et al., 2016; Zhang et al., 2017). Landslide causative factors often present nonlinear relationships (Corominas et al., 2014; Zhu et al., 2019). RF algorithm is able to catch such nonlinear features among the factors and also to prevent overfitting (Breiman, 2001; Goetz et al., 2015; Arabameri et al., 2020).

In view of the reliable prediction result obtained from regression and classification with the RF algorithm (Wu et al., 2016; Wu et al., 2018), the objective of this study is to employ this algorithm, one of the data-driven methods, to model the landslide risk taking Ruijin County as an example. As $\mathrm{RF}$ algorithm has been rarely applied to landslide study, one specific objective of this research is to find out an operational RF-based approach for this kind of geohazard zoning and mapping.

\section{Data and Methods}

\subsection{The study area}

Ruijin County is located in the southeast of Jiangxi Province, China, extending from $115^{\circ} 41^{\prime}$ $10^{\prime \prime}$ to $116^{\circ} 21^{\prime} 49^{\prime \prime} \mathrm{E}$ in longitude and from $25^{\circ} 32$ ' $15^{\prime \prime}$ to $26^{\circ} 17^{\prime} 45^{\prime \prime} \mathrm{N}$ in latitude, covering an area of about $2436 \mathrm{~km}^{2}$ (Fig. 1). From the view of topography, the elevation of the study area varies from 70 to $1211 \mathrm{~m}$ with a mean of $324 \mathrm{~m}$ while the slope from 0 to $65^{\circ}$ with an average of $15^{\circ}$. Hydrologically, the main rivers are Meijiang, Mianjiang and Jiubao Rivers running through the study area as sub-tributaries of the Gongshui River watershed. The study area belongs to the subtropical humid climate zone and is characterized by four distinct seasons, sufficient rainfall and long frost-free period. Heavy rainfall often occurs from March to July, accounting for more than $50 \%$ of the annual rainfall with amount of about $1663.5 \mathrm{~mm}$, an average of the period from 1968 to 2017. The annual mean temperature is $21.54^{\circ} \mathrm{C}$ and July is the hottest month of the year with a mean temperature of $28.8^{\circ} \mathrm{C}$.

The hot and humid weather leads to severe weathering of rock mass giving rise to formation of a thick weathered crust in which most landslides take places. From the human side, artificial cutting on slope for infrastructure construction (such as roads and highways) and housing development provoke instability of the crust mass causing landslides. 


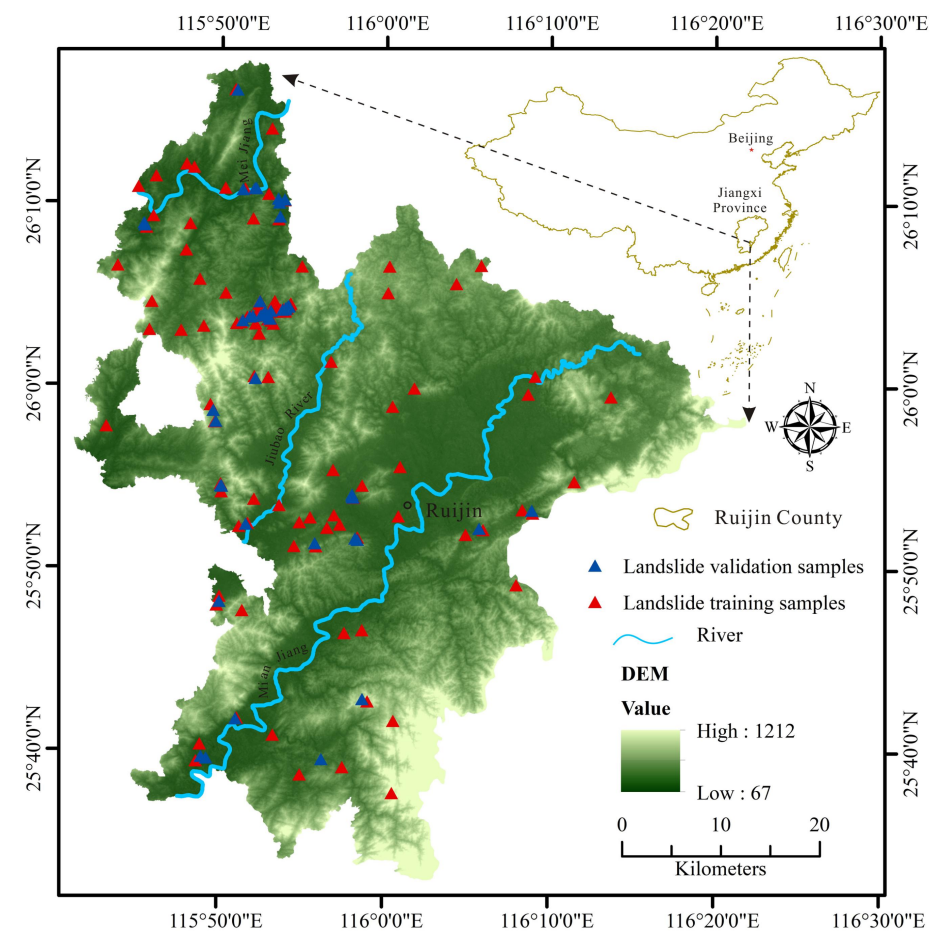

Fig. 1 Location of the study area, Ruijin County, Jiangxi, China and location of the training and validation sites of landslides in the study area.

\subsection{Data and Processing Procedures}

For landslide risk assessment, it is unavoidable to deal with non-digital geo-environmental data such as geological strata, faults, rivers as they are essential for this purpose. It is hence necessary to convert them into digital and meaningful values so that they can be incorporated as quantitative variables for landslide risk modeling. The global methodological procedure includes data pre-processing, digitization, linear features buffering, rational numeric value assignment to descriptive factors and buffers, risk modeling and validation, and finally accuracy assessment. These procedures are presented in a flowchart shown in Fig. 2. 


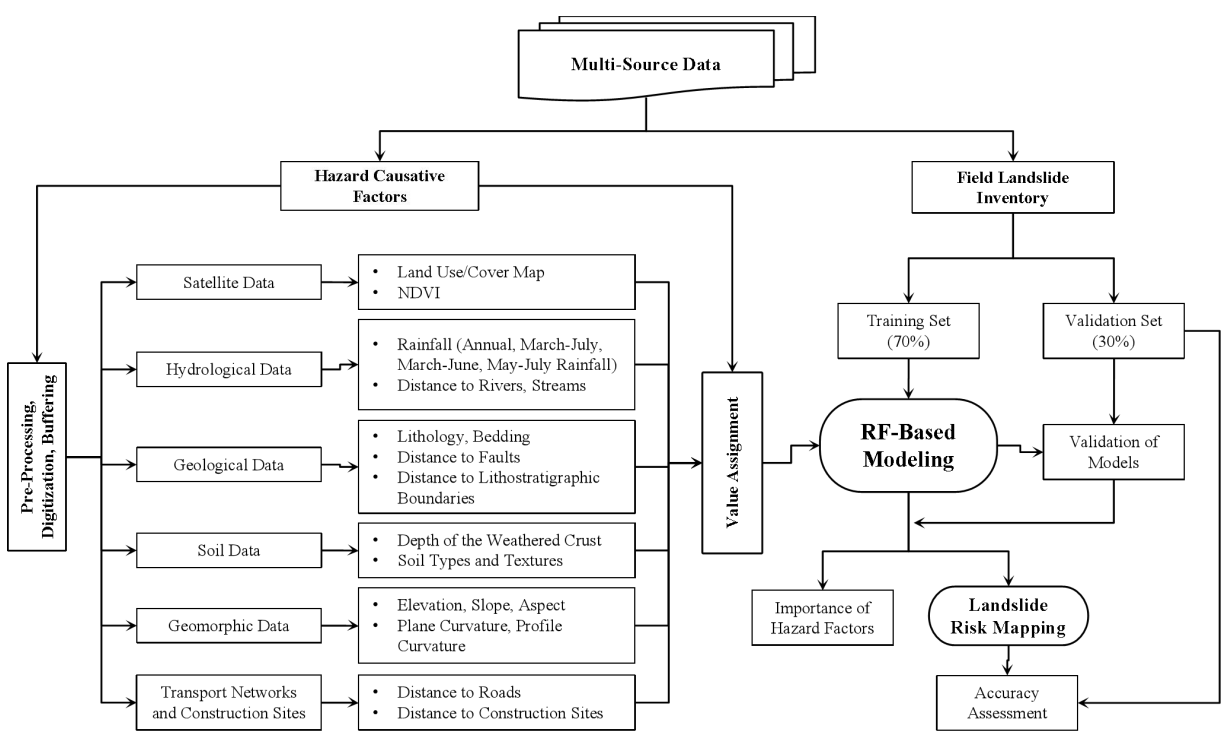

Fig. 2 Methodological flowchart.

\subsubsection{Geospatial and geo-environmental data}

\subsubsection{Satellite data}

1) Landsat imagery: Landsat 5 TM images of October and November 2006-2010, and Landsat 8 OLI images dated May 2017 and Sept 2019 were obtained from the USGS data server (https://glovis.usgs.gov). After atmospheric correction using COST model (Chavez, 1996; Wu, 2003 and Wu et al., 2013), Landsat 8 images were used for land cover mapping using the approach proposed by $\mathrm{Wu}$ et al. (2016) and Landsat 5 data for deriving the averaged multiyear autumn NDVI (Fig. 3a). In general, vegetation can help soil hold water content and improve its mechanical properties through root system to stabilize slopes. Thus, landslides may arise more likely in unvegetated areas rather than in vegetated ones (Montgomery et al., 2000; Reichenbach et al., 2014). However, this will be completely different when slope is cut or excavated because of road construction or housing development.

2) Very high resolution images: those are available on Google Earth as a complementary source of ground-truth data. The road and river networks were also extracted from Google Earth (Fig. 3b, 4d).

According to the principle of RF algorithm, we shall use two types of samples for modeling as input variables: one is the locality of landslides that have taken places and the other is the stable areas where landslides are unlikely to occur (Frattini et al., 2010; Depicker et al., 2020; Arabameri, 2020). Identified on Google Earth, the stable areas are places where slope is less than five degree, e.g., water bodies, urban areas, and cultivated land. Landslides with an area greater than $900 \mathrm{~m}^{2}(1$ Landsat pixel) that had been overlooked during the field observation were also identified and delineated on Google Earth.

\subsubsection{Hydrological data}

1) Rainfall: Rainfall is the main factor triggering landslides (Monsieurs et al., 2018; Depicker et al., 2020). Depicker et al. (2020) stated that rainfall condition was the direct cause of many 
shallow landslides. Daily rainfall data from Jan 2008 to Dec 2013 were obtained from 40 meteorological stations in Ruijin County and its adjacent areas. As landslides mainly occurred in March to July, especially in June and July but without recorded occurrence time, our intention was to investigate which months of rainfall may best reveal its role in landslide events. Thus, apart from the mean annual rainfall, March-June rainfall, May-July rainfall and March-July rainfall of these six years were also aggregated and gridded into raster with $30 \mathrm{~m}$ pixel size using Inverse Distance Weighting (IDW) approach.
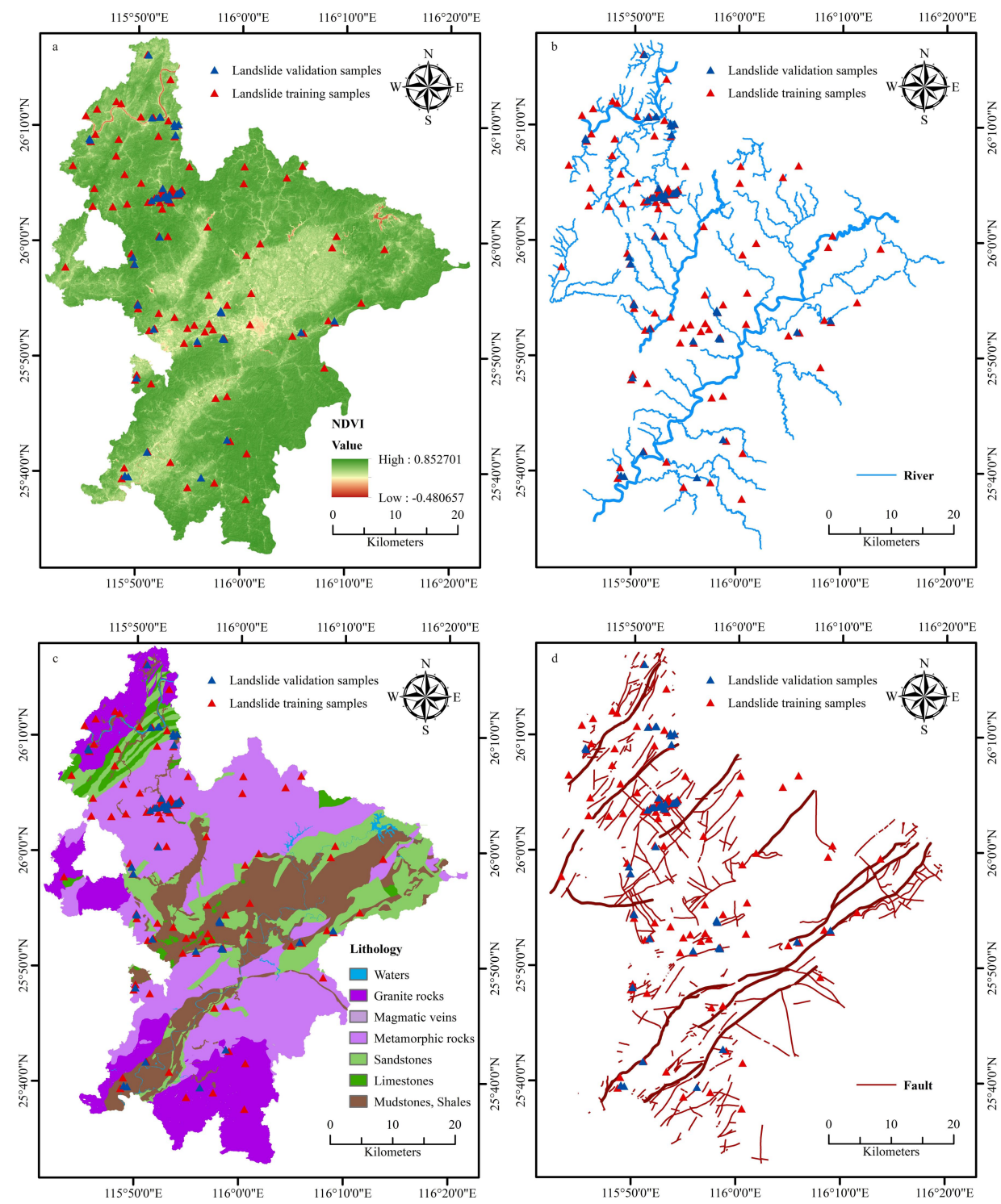
2) River network: The influence of rivers on the occurrence of landslides is reflected by the proximity to, or rather, the distance to them (Chen et al., 2018a; Cao et al., 2019; Arabameri et al., 2019). Thus, the rivers were vectorized from Google Earth (Fig. 3b) and buffered into belts with an interval of 30,60,90, 120 and $150 \mathrm{~m}$, respectively, for streams and 60,120, 180, 240 and $300 \mathrm{~m}$ respectively for the main rivers. Then, these buffers were assigned values in terms of their propensity or their importance in the event of landslide. For example, for the main rivers buffers of 0-60, 60-120, 120-180, 180-240 and 240-300 m were respectively assigned with 20, 15, 10, 5 and 1 while for streams, buffer zones of 0-30, 30-60, 60-90, 90-120 and 120-150 m respectively with 10 , 8,64 and 1 . This implies that the closer to the river the higher propensity of landslide.

Finally, these buffers are converted to raster data with $30 \mathrm{~m}$ cell size using the "Polygon to Raster" tool as proposed by Wu et al. (2018).

\subsubsection{Geological and geomorphic data}

1) Geological strata and formations: Geological strata were extracted from $1 / 50,000$ Geological Map. Except for Ordovician, Silurian, Triassic and Tertiary, the strata of other geological periods are mostly exposed. In terms of texture and composition, the lithology of different strata in the study area can be divided into 113 classes. To facilitate the geohazard analysis, these lithological classes were further aggregated into six main categories: (1) granitic rocks, (2) magmatic veins, (3) metamorphic rocks, (4) sandstone, (5) limestone, (6) mudstone and shales as shown in Fig. 3c. Just based on lithology and in absence of faults and joints, granitic massif would possess the highest resistance while mudstone the lowest to landslides. Hence, from (1) to (6), the propensity is likely to increase and they were respectively assigned values 1, 2, 3, 5, 7 and 10 .

According to the field observation, landslide events occurred frequently on the boundaries between two formations, especially, between the Quaternary sediments and other strata. Therefore, the lithostratigraphic boundary factor was also obtained by buffering and rasterization, then added to analyze the landslide risk.

2) Faults: This kind of geological structure has a prominent effect on the stability of rock mass (Smets et al, 2016; Delvaux et al., 2017). There formed the spectacular thrust nappe structure which was characterized by strong faulting activity in the study area. Such structure is accompanied with a series of faults and folds, which tend to be the landslide-prone areas, e.g., the fragile belts related to fold hinges, fracture zones and joints. As a matter of fact, the proximity to fault plays a role in such hazard events, i.e., the closer to the fault, the higher risk of landslide may exist. For this reason, the faults in the study area (Fig. 3d) were divided into three groups in terms of scale, i.e., big faults if their length is $>10-20 \mathrm{~km}$, medium faults if they are 2-10 km, and small faults if they are $<2 \mathrm{~km}$. The big faults were buffered into five zones of 0-120 m, 120-240 m, 240-360 m, 360-480 m and 480-600 m, and were respectively assigned with values of 20,15, 10, 5 and 1 . For the medium ones, they were also buffered into five zones of 0-60 m, 160-120 m, 120-180 m, 180-240 m and 240-300 $\mathrm{m}$ with assigned values of $10,8,6,4$ and 1 . The small faults were again buffered into five zones of 0-30 m, 30-60 m, 60-90 m, 90-120 m and 120-150 m and respectively assigned with 5, 4, 3, 2 and 1. These fault buffers were gridded into raster layer of $30 \mathrm{~m}$ in resolution.

3) Depth of the weathered crust, soil type and texture: Weathering is the process converting rocks into soils to constitute the weathered crust of our land surface. Landslides mostly take place in this crust in which soil texture seems of significant impact on (Kitutu et al., 2009) and the variability of soil types and depths of the crust play a part in the occurrence of such events (Fan et 
al., 2016). Because different soil types and textures have different sand percentage, grain sizes and porosity affecting the permeation of rain water. If liquidized by penetrated water, the crust bottom (soil/rock interface) may serve as slip surface of landslides as friction and resistance from the underlying rocks are reduced by this process. As soon as it has reached certain threshold, landslide occurs. Thus, the crust depth, i.e., the depth of the slippery soil/rock interface, is a plausible

Here the data of soil types were obtained from the Bureau of Jiangxi Coal Geology and the sand percentage $(\%)$, in which high sand percentage (low percentage of clay but high porosity) seems favorable for permeation of rain water and provoking landslide event, was considered as an indicator of soil contribution. Hence, soils with sand percentage $>40 \%, 30-40 \%, 20-30 \%, 10-12 \%$, $5-10 \%$ and $0-5 \%$, were respectively assigned with values of $10,8,6,4,2$ and 1 . At last soil proneness map was converted into raster of $30 \mathrm{~m}$ resolution.

The depth data of the weathered crust were obtained from the field 1282 measurements. In assumption that all the ridges have a crust of $0.5 \mathrm{~m}$ in depth, these field observed depths were interpolated using Kriging approach, then converted into raster layer of $30 \mathrm{~m}$ resolution.

4) Geomorphic data: Slope (angle) is a key driver of landslides and a triggering angle threshold of $28^{\circ}-38^{\circ}$ was reported by Fan et al.(2016); at the same time, elevation, aspect, plane curvature and profile curvature may also contribute to the occurrence of the hazards (Corominas et al., 2014; Guzzetti et al., 2005; Galli et al., 2008; Pourghasemi and Kerle, 2016; Cao et al., 2019). The ASTER GDEM data with a spatial resolution of $30 \mathrm{~m}$, jointly developed by METI of Japan and NASA of the United States, were obtained for Ruijin County from the Geospatial Data Cloud (http://www.gscloud.cn/) and used to derive elevation, slope, aspect, plane and profile curvatures (Fig. 1, Fig. 4a, 4b).

\subsubsection{Land use/cover, transport system and construction sites}

Using the classification approach proposed by $\mathrm{Wu}$ et al. (2016), land cover mapping was achieved for Ruijin with an accuracy of $90.99 \%$. The main land cover type is forests $(54.25 \%)$, followed by shrub/woodlands $(29.33 \%)$, croplands $(6.65 \%)$, artificial areas (urban, villages, road and other infrastructures, 5.36\%), barelands (1.45\%) and waters (1.41\%) (Fig. 4c). Forests cover hills and mountains, artificial areas and croplands are mainly distributed in lowlands (valleys) with low slope. For risk modeling purpose, forest cover was considered of low proneness and assigned a value of 1-2. On the contrary, unvegetated hilly slopes and barelands were regarded of high propensity and assigned a value of 10, while zero-slope croplands, urban and water-bodies were treated as non-risk (zero probability) areas. At the same time, NDVI can be used as an indicator of vegetation greenness and abundance, indirectly representing the development degree of the root system. For barelands, woodlands and forests, NDVI shall be a good indicator of propensity of landslide.

Road construction is one of the important human activities leading to slope failure (García-Rodríguez et al., 2008; Cao et al., 2019). Similarly, housing development along two sides of the roads or on the brink of hills by cutting slopes constitutes also an important factor making the slope massif unstable. The influence of road on landslide is also reflected by the distance to them (Chen et al., 2018a; Cao et al., 2019; Arabameri et al., 2020). The road system (Fig. 4d) was also assigned values the same as was done for rivers and faults. 

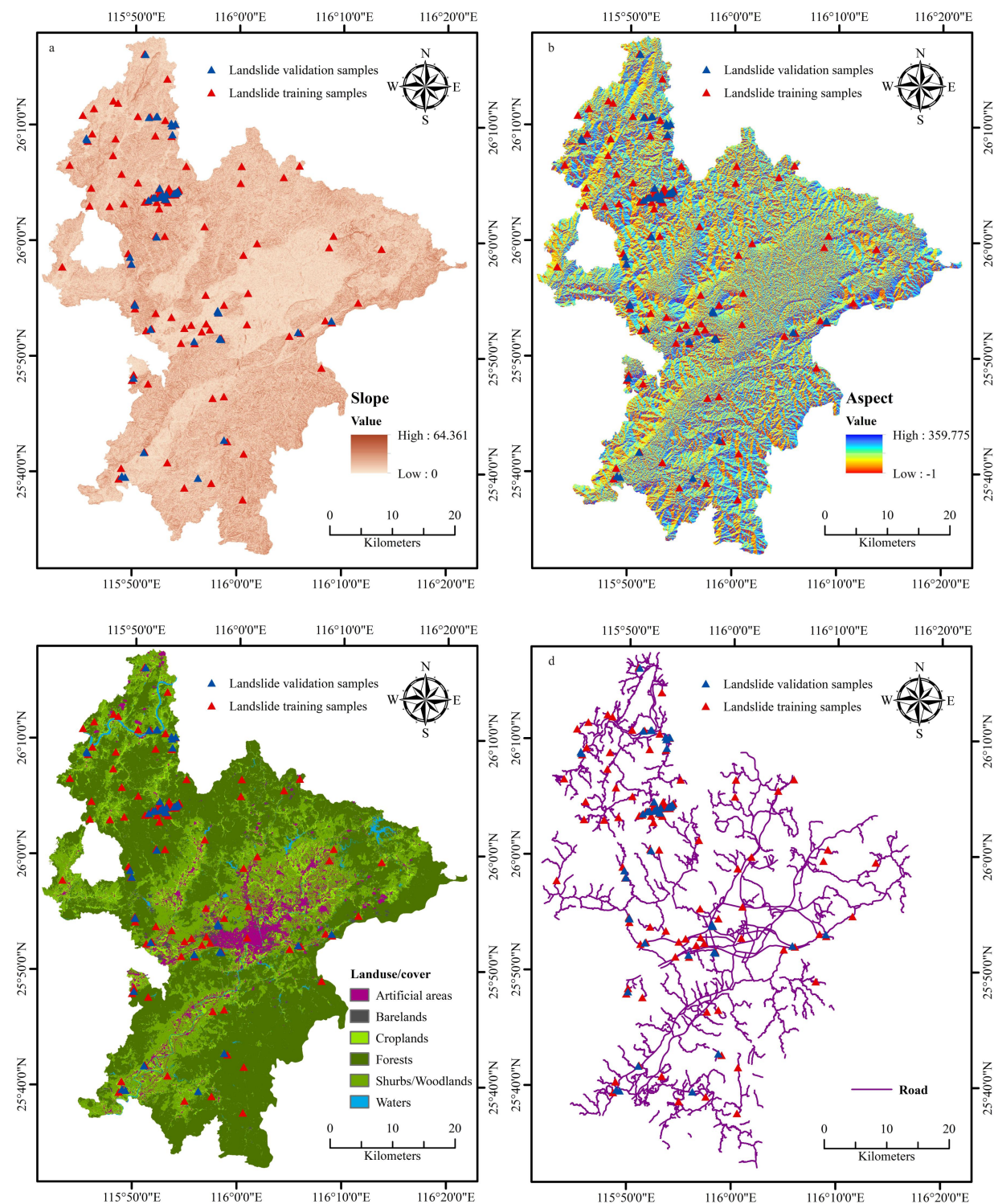

Fig. 4 Landslide hazard factors: (a) Slope, (b) Aspect, (c) Land use/cover, and (d) Roads.

There were no landslide accidents recorded in the study area caused by earthquakes, so the earthquake factor was not considered in this study.

\subsubsection{Integrated geo-environmental dataset}

The occurrence of landslide is a result of the combined action of all the causative geo-environmental factors (Corominas et al., 2014; Zhu, et al., 2019). In this study, all these factors that may contribute to the occurrence of landslide will be considered for risk modeling. The above processed raster layers namely geological strata, proximity to faults, to lithostratigraphic boundaries, to roads and to to rivers, depth of the weathered crust, soil types and texture, elevation, slope, aspect, 
plane curvature, profile curvature, land use/cover, NDVI, multiyear mean annual rainfall, multiyear mean May-July rainfall, multiyear mean March-June rainfall, multiyear mean March-July rainfall were incorporated into a 19-band dataset in Datum WGS 84 and Projection UTM 50 by Layer Stacking function. These raster layers were considered as hazard-causative factors or independent hazard predictors.

\subsubsection{Field data}

First-hand data were obtained from the field observation during the Geological Hazard Survey Campaign in Ruijin County on a scale of $1 / 50,000$ by the 264 Geological Team of Jiangxi Nuclear Industry in the recent years. The realistic landslides that had occurred in the past ten years were investigated and recorded. Some landslides had been missed during the field observation were digitized on Google Earth as a complement to the former. In total, 155 historical landslide cases were collected. The landslide sites ranged from $20 \mathrm{~m}^{2}$ to $64000 \mathrm{~m}^{2}$ in size. Most of the landslides are small in scale, i.e., less than $900 \mathrm{~m}^{2}$ in study area. To obtain the optimal spatial presentation of samples for RF modeling, the landslide points with areas less than $900 \mathrm{~m}^{2}$ were buffered with radius of $30 \mathrm{~m}$ and then rasterized into pixels with size of $30 \mathrm{~m}$ (Wu et al., 2018), and those larger than $900 \mathrm{~m}^{2}$, a direct rasterization from vector was conducted. These cases were assigned a value of 1 , indicating that the events of landslide have truly taken places, i.e., the probability is 1 .

As mentioned above, the non-risk areas (low-slope $\left(<1-5^{\circ}\right)$ valleys, plain, urban and water-bodies) were integrated into the field dataset as zero-risk area, i.e., the risk probability is 0 .

At last, we randomly selected $70 \%$ of the landslide samples (109 cases) plus $70 \%$ of the non-risk zones to constitute a training set (TS) and used the remained ones (45 cases, $30 \%$ ) as a validation set (VS).

\subsection{Landslide risk modeling}

Among the machine learning algorithms, Wu et al (2016 and 2018) found that RF and support vector machines (SVM) performed equally well in classification, better than artificial neural networks (ANN), but RF performed best in regression prediction. Hence, RF classification algorithm was selected for geohazard risk modeling in this study. The overall procedure was summarized in Fig. 2 and the detail on modeling, validation and accuracy assessment is given in the following sections.

\subsubsection{RF classification of risk probability}

RF classification, based on growing decision trees, is an ensemble of tree classifiers that allow to conduct classification by predicting the probability of a given pixel to be classified into the target class through majority voting. The key technique of this algorithm lies in that a bootstrap sample of the TS is used to build each tree, and a stochastic selection of the input variables is searched to determine the best split for each node. Meanwhile, RF algorithm uses out-of-bag (OOB) estimates to define the generalization error and the importance of each variable (Breiman, 2001). RF will not overfit if the number of decision trees (NT) increases to certain level. Thence, NT should be large enough to reduce the OOB error of classification to a stable level in the training process. It is to mention here that instead of classification of land cover types, we employ this algorithm to classify the probability of risk and non-risk for each pixel. 


\subsubsection{Application of RF algorithm}

In this study, RF classification was conducted within EnMap-Box which is a package particularly developed to process and analyze image data (Waske et al., 2012). While conducting RF modeling, we kept the combined 19-band dataset as input variables with 109 landslides used as TS and 45 as VS. Some key parameters of RF classification include the Impurity Function, the Stop Criteria (for node splitting), the Number of randomly selected Features (or Number of Variables) at each node and Number of Trees (NT) with classification and regression algorithm (Wu et al., 2016, 2018).

The Gini Coefficient was selected for the Impurity Function. The Stop Criteria was set as the default values which was a Minimum number of samples at a node of 1 or a Minimum impurity calculated based on the Gini index of 0 . The Number of randomly selected Features (or Number of Variables) at each node was the square root of all available features. The default value of number of trees was 100 within EnMap-Box. In this study, NT was set to 300 and 500 in order to achieve a better prediction.

After parameterization of RF classification model using the integrated dataset as predictive variables and TS for training and internal validation, the model was applied back to the integrated dataset for landslide prediction, i.e., the probability of landslide occurrence in each pixel. The accuracy of modeling is calculated versus the independent VS.

\subsubsection{Importance of variables}

The importance of variables in the RF classification can be evaluated by variable substitution method. In other words, it can be measured by calculating the difference of the OOB error before and after value substitution. Factor importance of $F_{i}$ can be expressed as follows:

$$
\operatorname{VIM}\left(F_{i}\right)=\frac{1}{N T} \sum_{t} \operatorname{errOOB}{ }_{t}^{i}-\operatorname{errOOB}_{t}
$$

where NT is the number of trees, $\operatorname{errOOB}_{t}$ is an error for tree $t$ of the forests when all the factors are included, $\operatorname{errOOB}{ }_{t}^{i}$ refers to an error after removing the factor $F_{i}$ and $\operatorname{VIM}\left(F_{i}\right)$ is variable importance for $F_{i}$. For RF classification and its result produced, a high value indicates that the factor is of high importance and vice versa.

\subsubsection{Validation of models}

Base on the Confusion Matrix, Precision, Recall, F1 index, Kappa Coefficient (KC) and Overall Accuracy (OA) can be calculated to evaluate the accuracy and performance of landslide risk prediction model (Congalton, 1983).

Generally, both TS and VS can be used to calculate these statistical indices. The evaluation results of TS show the adaptability of the model to the training data, while those of VS reveal the predictive and generalization ability of the model (Tien Bui et al., 2012).

According to previous studies, the smaller the high-risk area predicted by the model, the more historical landslide points concentrated there, which indicates that the model has high predictivity (Cao et al., 2019; Dou et al., 2019). The success rate curve and prediction rate curve can be made respectively by using the landslide risk prediction results of TS and VS. For the study area, the prediction accuracy of landslide risk map can be analyzed and demonstrated by the area under curve (AUC) features (Chung et al., 2003; Yilmaz, 2009; Nicu et al., 2019). 


\section{Results and Discussion}

\subsection{Landslide risk zoning}

The landslide risk zoning was achieved based on the modeled risk probability when RF modeling was implemented at $\mathrm{NT}=300$. All pixels were divided into four levels: low-risk (probability $<0.5$ ), medium-risk (probability $\geq 0.5$ and $<0.7$ ), high-risk (probability $\geq 0.7$ and $<0.9$ ) and extremely high-risk (probability $\geq 0.9$ ). The landslide risk map of Ruijin was hence produced (Fig. 5a).

The predicted results of the landslide-prone areas were largely consistent with the field survey: (1) High-risk zones were mainly linearly distributed along rivers and roads (Fig. 5b). Many landslides were often caused by river undercutting and artificial cutting for road construction and housing. (2) In the central part of the study area, high-risk zones are concentrated in the Quaternary soil layer, or rather, in the weathered crust, especially along the boundaries of lithologic strata (Fig. 5c). The Quaternary unconsolidated soil layer with loose structure provided rich material for landslides. The boundaries of lithologic strata behaved as unstable structural interfaces, which were important factors for landslides. (3) In the granitic massif, there were also obvious high-risk zones distributed along the roads (Fig. 5b, 5c). Weathering accelerated by humidity, high undulating landform and tectonically active settings of the study area, changed the intrinsic properties of the material and reduced the strength of the near-surface rocks.

Table 1 shows that $24.83 \mathrm{~km}^{2}$ of areas identified as Extremely high risk zones account for $1.02 \%$ of the total study area, and High, Medium and Low risk zones take up $227.57 \mathrm{~km}^{2}(9.32 \%)$, $472.39 \mathrm{~km}^{2}(19.36 \%)$ and $1715.60 \mathrm{~km}^{2}$ (70.30\%) respectively. Additionally, $94.19 \%$ of the field samples, i.e., the realistic landslides, took places in $10.34 \%$ of the entire study area, which was categorized as High-risk and Extremely-high risk zones in our risk zone map.

\subsection{Number of Trees with RF classification}

The selection of NT has a great influence on the accuracy of RF modeling. The performance of classification or regression is poor and the error is large when NT is small. As it grows, the OOB error decreases continuously and reaches eventually a threshold (Breiman, 2001). However, the complexity of RF model is directly proportional to NT. If there are too many decision trees, the operating efficiency will decrease as it becomes more time-consuming and the optimal result may not be obtained. The previous study by Wu et al. (2018) confirmed that in both low (e.g., 100) and high NT (e.g., 1000) cases, the algorithm did not perform well, but it did when NT was set to 300 and 500. .It is clear that the OOB error tends to be stable after NT gets greater than 300 (Fig. 6), or rather, the model accuracy becomes greater than $96 \%$. Hence, 300 was finally used for NT when performing landslide risk modeling. 


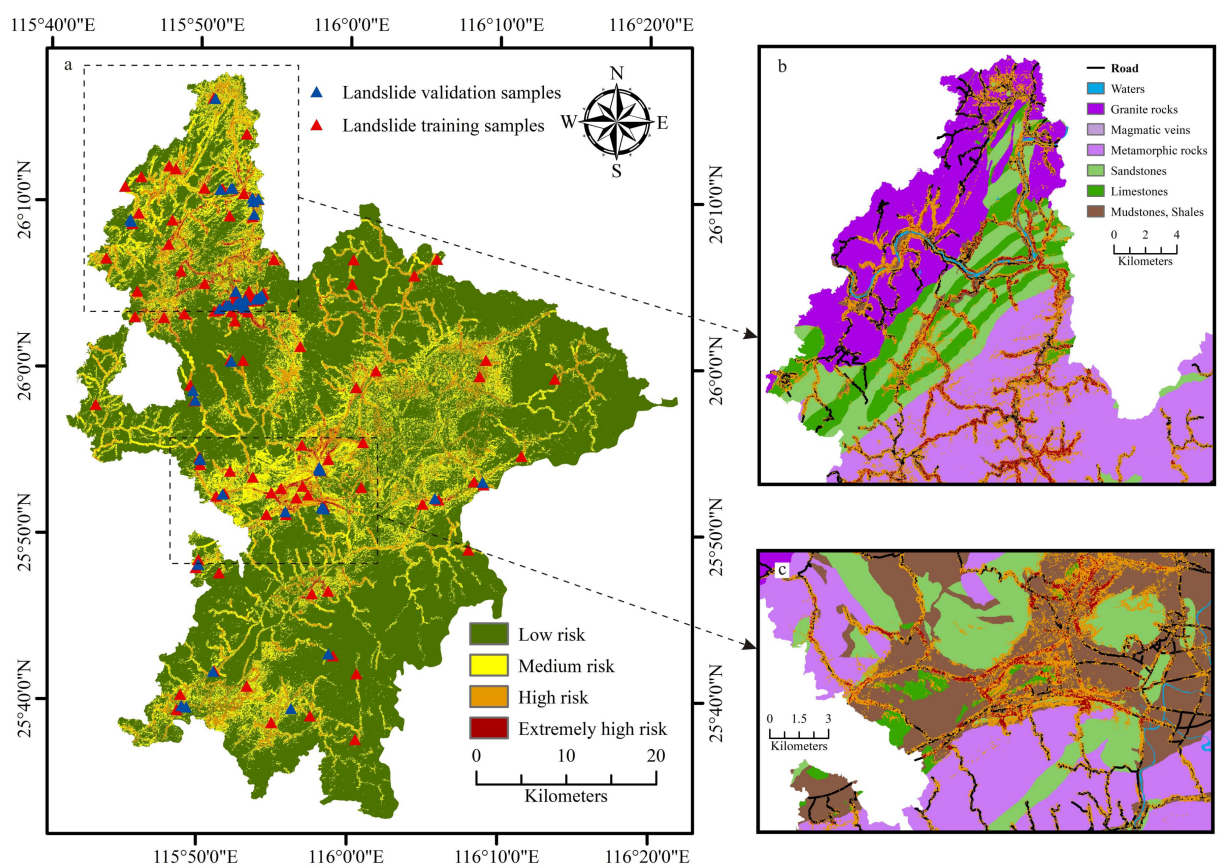

Fig. 5 The landslide risk zoning map of Ruijin County.

Table 1. Distribution of historical landslides within different risk levels

\begin{tabular}{ccccc}
\hline $\begin{array}{c}\text { Landslide Risk } \\
\text { Level }\end{array}$ & $\begin{array}{c}\text { Area } \\
\left(\mathbf{k m}^{\mathbf{2}}\right)\end{array}$ & $\begin{array}{c}\text { Area Percentages } \\
\mathbf{( \% )}\end{array}$ & $\begin{array}{c}\text { Number of Historical } \\
\text { landslides }\end{array}$ & $\begin{array}{c}\text { Number } \\
\text { Percentages (\%) }\end{array}$ \\
\hline Extremely high & 24.83 & 1.02 & 99 & 63.87 \\
High & 227.57 & 9.32 & 47 & 30.32 \\
Medium & 472.39 & 19.36 & 5 & 3.23 \\
Low & 1715.60 & 70.30 & 4 & 2.58 \\
\hline
\end{tabular}

\subsection{Importance of hazard factors}

For geohazard assessment, it is critical to understand the importance, more concretely, the role of each geo-environmental factor in such disaster event. In terms of the OBB error, Fig. 7 shows the importance of all the hazard factors considered in this research with the first four factors as follows: 1) distance to road, 2) slope, 3) May-July rainfall, 4) NDVI, 5) elevation, and so on. 


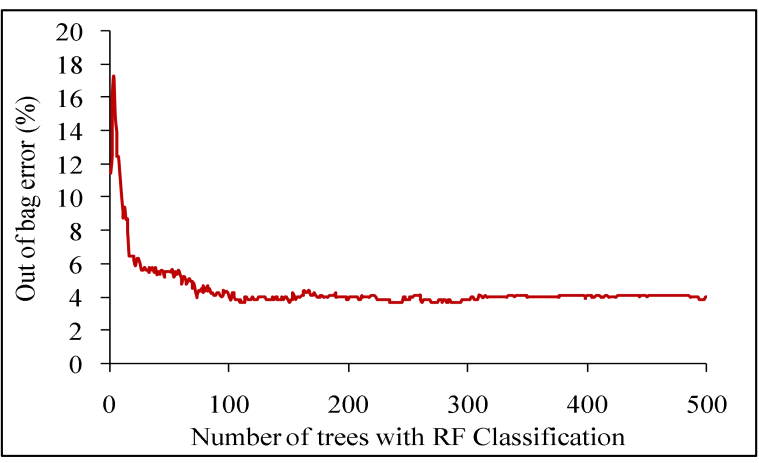

Fig. 6 Out-of-bag (OOB) error plot versus number of trees (NT) within RF modeling.

In the case of Ruijin, the order of importance seems plausible. Stable slope becomes unstable as a result of road construction, i.e., slope cutting or housing development, and naturally, steeper slope has higher propensity to slide due to gravity. May-July rainfall is a triggering factor as it liquidizes the slippery interface when it reaches certain threshold, i.e., the rainfall amount leading to saturation of soil after penetration and starting to flow on the soil/rock interface. Actually, the more rainfall in short time, the higher landslide disaster risk may be developed. Rainfall is thus widely employed as a Weather Indicator of landslides. NDVI, an autumn mean of five-year period and an indicator of vegetation abundance, vigor and root system development of forests and woodlands (herbaceous layer is mostly withered at that time), can largely reflect the stability and instability of the weathered crust. It is hence reasonable that these factors were identified as the most important hazard-causative factors in Ruijin though all others may play also a certain role in the geohazard events.

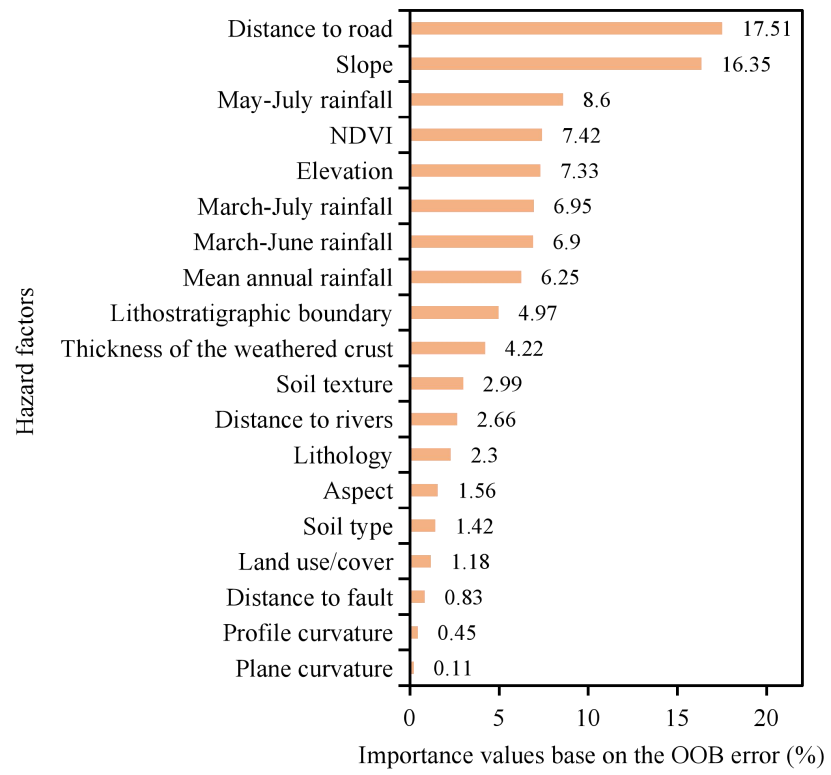

Fig. 7 Importance of the variables (geo-environmental factors) in provoking landslide events. 
The importance of hazard factors associated with landslides had been also discussed by other authors. The one of Dou et al. (2019) showed that precipitation was the most significant factor but according to those of Arabameri et al. (2017) and Cao et al. (2019), DEM was the most important one. Actually, it is understandable that in different geological environments, the mechanism of landslides may be different and so the importance of hazard factors.

\subsection{Validation of the modeling results}

Only after being validated, has the model potential to be applied elsewhere. We used five statistical indicators to evaluate the performance of landslide risk model, including Precision, Recall, F1 Index, $\mathrm{KC}$ and $\mathrm{OA}$ as mentioned above. Against the training dataset, the Precision, Recall, F1 Index, $\mathrm{KC}$ and $\mathrm{OA}$ of the modeled results were $0.9908,0.9818,0.9863,0.9724$ and 0.9862 , respectively, while they were $0.95,0.8867,0.9173,0.8299$ and 0.9149 respectively versus VS (Table 2). Above all, statistical indicators have shown that the RF classification model has good performances in predicting the landslide risk.

Table 2. Performance of the RF modeling vs training set (TS) and validation set (VS)

\begin{tabular}{ccc}
\hline Item & Training Set & Validation Set \\
\hline Precision (\%) & 99.08 & 95.00 \\
Recall (\%) & 98.18 & 88.67 \\
F1 Index (\%) & 98.63 & 91.73 \\
KC (\%) & 97.24 & 82.99 \\
OA (\%) & 98.62 & 91.49 \\
\hline
\end{tabular}

Fig. 8 presented the success rate curve and predicted rate curve versus TS and VS. The AUC for success rate curve and for prediction rate curve were 0.9936 and 0.9677 , respectively. A model can be considered as appropriate for this kind of risk prediction when the AUC had a value above 0.5 (Chen et al., 2018b; Achour and Pourghasemi, 2019). The landslide risk map had a better success and prediction rates by RF classification model in this study compared with the results of other scholars (Chung et al., 2003; Nicu, 2018; Depicker et al., 2020). Hence, RF classification algorithm has a good predictive capability, and can be extended elsewhere for application.

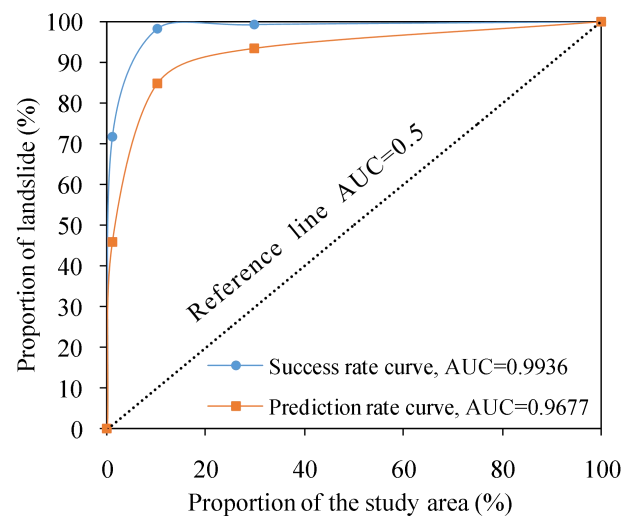




\subsection{Case verification}

The landslides in the newly-built campus of No. 6 Middle School and the Longzhu Temple in Ruijin took place very recently. The two new landslide events were predicted as Extremely high-risk zones in the risk map (Fig. 9a). During the field investigation in July 2019, the middle school was closed due to this disastrous effect (Fig. 9b); at the Longzhu Temple there were significant ground bulges along the behind and side wall feet because of the extrusion provoked by the downward slide of the upper slope (Fig. 9c). Thus, both sites are in danger as landslides continue gradually.

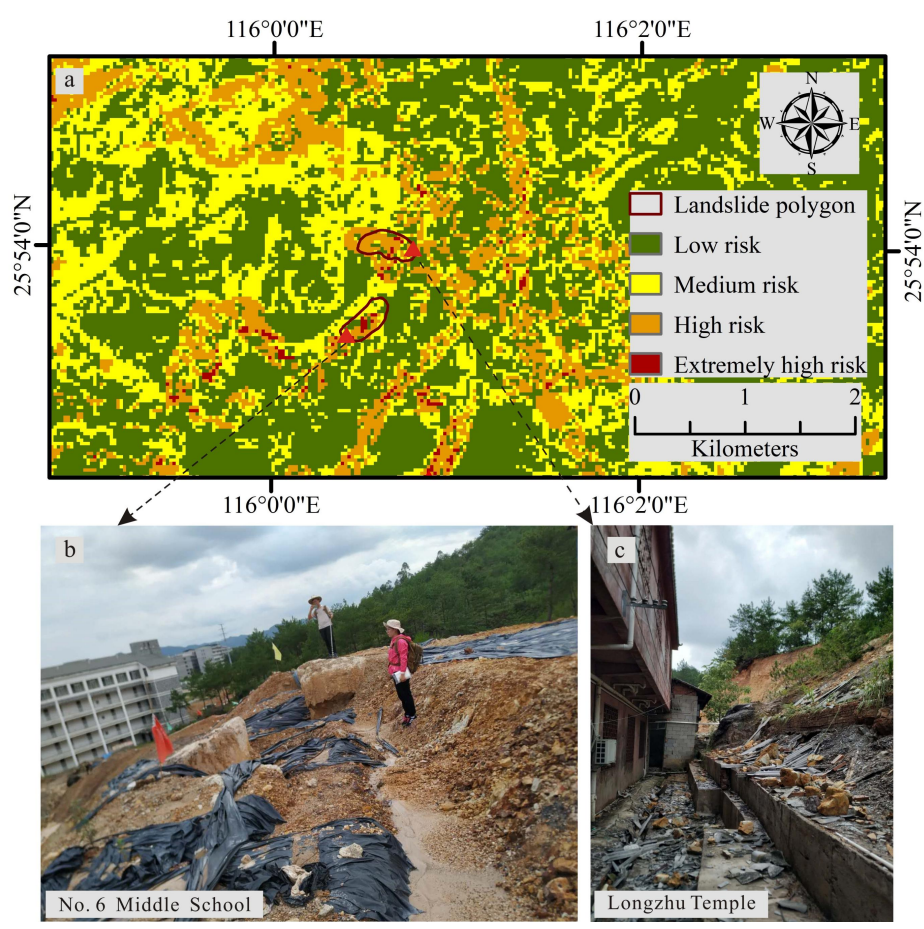

Fig. 9 The landslide risk zoning map and photographs of landslide in field survey.

\section{Conclusions}

The prediction and prevention of landslide disasters have become essential to secure our society. This paper presents a research using multi-source geo-environmental dataset as input variables followed by a RF Classification to model and predict the landslide risk in Ruijin County. Our results were obtained with high reliability of which OA is $98.62 \%$ and $91.49 \%$ versus TS and VS. We believe that our research will be helpful for local government to take action on prevention and early warning of geohazard to ensure people's safety and property, and to provide theoretical advice for the infrastructure construction and urban planning.

Our study revealed the critical role of human activity, in particular, road construction, in landslide events. Most of the observed landslides in Ruijin were actually "man-made". In future road development we should take its negative impacts into account. 
Another innovation lies in finding out a rational digitization and value assignment approach for non-digital geo-environmental factors such as geological strata, faults, soil, roads and rivers so that quantitative risk modeling and prediction using RF algorithm can be smoothly achieved.

Our study also illustrates that combination of remote sensing, geological, geomorphic, climatic and human dimensional data is relevant for such geohazard risk zoning and mapping. RF algorithm is able to satisfactorily achieve such task. This study can hence serve as a prototype for similar research elsewhere.

\section{Acknowledgments}

This research was supported by the Start-up Fund for Scientific Research of the East China University of Technology, granted to Dr Weicheng Wu (Grant No. DHTP2018001), who is also supported by the Jiangxi Talent Program, and the Special Innovation Fund for Postgraduate of the East China University of Technology to Ms Xiaoting Zhou. Field investigation during July, October 2019 was received, the first-hand field landslide observation data and the 1/50,000 Scale Geological Map of Ruijin were provided by the 264 Geological Team of Jiangxi Nuclear Industry.

Conflicts of Interest: The authors declare no conflict of interest.

Author Contributions: Conceptualization, X.Z., W.W. and Z.L.; methodology, W.W. and X.Z.; software, W.W.; validation, X.Z., J.J., M.Z. and Y.L.; formal analysis, X.Z., P.O., W.H. and Y.Z.; investigation, X.Z., W.W., Y.S., Z.W., P.O., W.H., Y.Z., L.X. and X.H.; resources, G.Z., R.C., Y.S., Z.W. and T.L.; data curation, X.Z., P.O., W.H. and Y.Z.; writing - original draft preparation, X.Z. and W.W; writing - review and editing, W.W.; visualization, F.X. and J.L.; supervision, W.W., Y.Q., S.P., C.S., Y.B., X.Z., X.L., and W.L.; project administration, W.W. and G.Z.; funding acquisition, W.W. All authors have read and agreed to the published version of the manuscript.

\section{References}

Achour, Y. and Pourghasemi, H. R.: How do machine learning techniques help in increasing accuracy of landslide susceptibility maps?, Geoscience Frontiers., doi:10.1016/j.gsf.2019.10.001, 2019.

Aleotti, P. and Chowdhury, R.: Landslide hazard assessment: summary review and new perspectives, Bulletin of Engineering Geology \& the Environment., 58, 21-44, doi: 10.1007/s100640050066, 1999.

Arabameri, A., Pourghasemi, H. R., and Yamani, M.: Applying different scenarios for landslide spatial modeling using computational intelligence methods, Environmental Earth Sciences., 76, doi:10.1007/s12665-017-7177-5, 2017.

Arabameri, A., Roy, J., Saha, S., Blaschke, T., Ghorbanzadeh, O., and Tien Bui, D.: Application of Probabilistic and Machine Learning Models for Groundwater Potentiality Mapping in Damghan Sedimentary Plain, Iran. Remote Sensing., 11, doi:10.3390/rs11243015, 2019.

Arabameri, A., Saha, S., Roy, J., Chen, W., Blaschke, T., and Tien Bui, D.: Landslide Susceptibility Evaluation and Management Using Different Machine Learning Methods in The Gallicash River Watershed, Iran, Remote Sensing., 12, doi:10.3390/rs12030475, 2020. 
Assilzadeh, H., Levy, J. K., and Wang, X.: Landslide Catastrophes and Disaster Risk Reduction: A GIS Framework for Landslide Prevention and Management, Remote Sensing., 2, 2259-2273, doi:10.3390/rs2092259, 2010.

Ayalew, L. and Yamagishi, H.: The application of GIS-based logistic regression for landslide susceptibility mapping in the Kakuda-Yahiko Mountains, Central Japan, Geomorphology., 65, 15-31, doi:10.1016/j.geomorph.2004.06.010, 2005.

Breiman, L.: Random Forests, Machine Learning., 45, 5-32, doi:10.1023/A:1010933404324, 2001.

Cao, J., Zhang, Z., Wang, C., Liu, J., and Zhang, L.: Susceptibility assessment of landslides triggered by earthquakes in the Western Sichuan Plateau, Catena., 175, 63-76, doi:10.1016/j.catena.2018.12.013, 2019.

Chang, Z., Du, Z., Zhang, F., Huang, F., Chen, J., Li, W., and Guo, Z.: Landslide Susceptibility Prediction Based on Remote Sensing Images and GIS: Comparisons of Supervised and Unsupervised Machine Learning Models, Remote Sensing., 12, doi:10.3390/rs12030502, 2020.

Chavez, P. S.: Image-Based Atmospheric Correction-Revisited and Improved, Photogrammetric Engineering \& Remote Sensing., 62, 1025-1036, doi:10.1016/0031-0182(96)00019-3, 1996.

Chen, W., Xie, X., Peng, J., Shahabi, H., Hong, H., Bui, D. T., Duan, Z., Li, S., and Zhu, A. X.: GIS-based landslide susceptibility evaluation using a novel hybrid integration approach of bivariate statistical based random forest method, Catena., 164, 135-149, doi:10.1016/j.catena.2018.01.012, 2018a.

Chen, W., Zhang, S., Li, R., and Shahabi, H.: Performance evaluation of the GIS-based data mining techniques of best-first decision tree, random forest, and naive Bayes tree for landslide susceptibility modeling, Sci Total Environ., 644, 1006-1018, doi:10.1016/j.scitotenv.2018.06.389, 2018b.

Chung, C. J. F. and Fabbri, A. G.: Validation of spatial prediction models for landslide hazard mapping, Natural Hazards., 30, 451-472, doi:10.1023/B:NHAZ.0000007172.62651.2b, 2003.

Congalton, R. G.: Assessing Landsat classification accuracy using discrete multivariate analysis statistical techniques, Photogramm.eng.remote Sens., 49, 1003-1007, doi:10.1271/bbb1961.44.1003, 1983.

Corominas, J., van Westen, C., Frattini, P., Cascini, L., Malet, J. P., Fotopoulou, S., Catani, F., Van Den Eeckhaut, M., Mavrouli, O., Agliardi, F., Pitilakis, K., Winter, M. G., Pastor, M., Ferlisi, S., Tofani, V., Hervas, J., and Smith, J. T.: Recommendations for the quantitative analysis of landslide risk, Bulletin Of Engineering Geology And the Environment., 73, 209-263, doi:10.1007/s10064-013-0538-8, 2014.

Delvaux, D., Mulumba, J. L., Sebagenzi, M. N. S., Bondo, S. F., Kervyn, F., and Havenith, H. B.: Seismic hazard assessment of the Kivu rift segment based on a new seismotectonic zonation model (western branch, East African Rift system), Journal Of African Earth Sciences., 134, 831-855, doi:10.1016/j.jafrearsci.2016.10.004, 2017.

Depicker, A., Jacobs, L., Delvaux, D., Havenith, H. B., Maki Mateso, J. C., Govers, G., and Dewitte, O.: The added value of a regional landslide susceptibility assessment: The western branch of the East African Rift, Geomorphology., 353, doi:10.1016/j.geomorph.2019.106886, 2020.

Devkota, K. C., Regmi, A. D., Pourghasemi, H. R., Yoshida, K., Pradhan, B., Ryu, I. C., Dhital, M. R., and Althuwaynee, O. F.: Landslide susceptibility mapping using certainty factor, index of entropy and logistic regression models in GIS and their comparison at Mugling-Narayanghat road section in Nepal Himalaya, Natural Hazards., 65, 135-165, doi:10.1007/s11069-012-0347-6, 2012.

Dou, J., Yunus, A. P., Tien Bui, D., Merghadi, A., Sahana, M., Zhu, Z., Chen, C. W., Khosravi, K., Yang, Y., and Pham, B. T.: Assessment of advanced random forest and decision tree algorithms for modeling 
rainfall-induced landslide susceptibility in the Izu-Oshima Volcanic Island, Japan, Sci Total Environ., 662, 332-346, doi:10.1016/j.scitotenv.2019.01.221, 2019.

Fan, L., Lehmann, P., and Or, D.: Effects of soil spatial variability at the hillslope and catchment scales on characteristics of rainfall-induced landslides, Water Resources Research., 52, 1781-1799, doi:10.1002/2015WR017758, 2016.

Frattini, P., Crosta, G., and Carrara, A.: Techniques for evaluating the performance of landslide susceptibility models, Engineering Geology., 111, 62-72, doi:10.1016/j.enggeo.2009.12.004, 2010.

Froude, M. J. and Petley, D. N.: Global fatal landslide occurrence from 2004 to 2016, Natural Hazards And Earth System Sciences., 18, 2161-2181, doi:10.5194/nhess-18-2161-2018, 2018.

Furlani, S. and Ninfo, A.: Is the present the key to the future?, Earth-Science Reviews., 142, 38-46, doi:10.1016/j.earscirev.2014.12.005, 2015.

Gallen, S. F., Clark, M. K., and Godt, J. W.: Coseismic landslides reveal near-surface rock strength in a high-relief, tectonically active setting, Geology., 43, 11-14, doi:10.1130/g36080.1, 2014.

Galli, M., Ardizzone, F., Cardinali, M., Guzzetti, F., and Reichenbach, P.: Comparing landslide inventory maps, Geomorphology., 94, 0-289, doi:10.1016/j.geomorph.2006.09.023, 2008.

García-Rodríguez, M. J., Malpica, J. A., Benito, B., and Díaz, M.: Susceptibility assessment of earthquake-triggered landslides in El Salvador using logistic regression, Geomorphology., 95, 172-191, doi:10.1016/j.geomorph.2007.06.001, 2008.

Genuer, R., Poggi, J. M., and Tuleau Malot, C.: Variable selection using random forests, Pattern Recognition Letters., 31, 2225-2236, doi:10.1016/j.patrec.2010.03.014, 2010.

Goetz, J. N., Brenning, A., Petschko, H., and Leopold, P.: Evaluating machine learning and statistical prediction techniques for landslide susceptibility modeling, Computers \& Geosciences., 81, 1-11, doi:10.1016/j.cageo.2015.04.007, 2015.

Gritzner, M. L., Marcus, W. A., Aspinall, R., and Custer, S. G.: Assessing landslide potential using GIS, soil wetness modeling and topographic attributes, Payette River, Idaho, Geomorphology., 37, 149-165, doi:10.1016/s0169-555x(00)00068-4, 2001.

Guzzetti, F., Carrara, A., Cardinali, M., and Reichenbach, P.: Landslide hazard evaluation: a review of current techniques and their application in a multi-scale study, Central Italy, Geomorphology., 31, 181-216, doi:Doi 10.1016/S0169-555x(99)00078-1, 1999.

Guzzetti, F., Reichenbach, P., Cardinali, M., Galli, M. and Ardizzone, F.: Probabilistic landslide hazard assessment at the basin scale, Geomorphology., 72, 272-299, doi:10.1016/j.geomorph.2005.06.002, 2005.

Huang, Y. and Zhao, L.: Review on landslide susceptibility mapping using support vector machines, Catena., 165, 520-529, doi:10.1016/j.catena.2018.03.003, 2018.

Kitutu, M. G., Muwanga, A., Poesen, J. and Deckers, J. A. Influence of soil properties on landslide occurrences in Bududa district, Eastern Uganda, African Journal Of Agricultural Research., 4, doi:611-620, 10.1021/jf900470c, 2009.

Li L. P., Lan H. X., Guo C. B., Zhang Y. S., Li Q. W., and Wu Y. M.: A modified frequency ratio method for landslide susceptibility assessment, Landslides., doi:10.1007/s10346-016-0771-x, 2017.

Monsieurs, E., Jacobs, L., Michellier, C., Basimike Tchangaboba, J., Ganza, G. B., Kervyn, F., Maki Mateso, J. C., Mugaruka Bibentyo, T., Kalikone Buzera, C., Nahimana, L., Ndayisenga, Aloys., Nkurunziza, P., Thiery, W., Demoulin, A., Kervyn, M., and Dewitte O.: Landslide inventory for hazard assessment in a 
data poor context: a regional-scale approach in a tropical African environment, Landslides., 15, 2195-2209, doi:10.1007/s10346-018-1008-y, 2018.

Montgomery, D. R. and Dietrich, W. E.: A physically based model for the topographic control on shallow landsliding, Water Resources Research., 30, doi: 10.1029/93wr02979, 1994.

Montgomery, D. R., Schmidt, K. M., Greenberg, H. M., and Dietrich, W. E.: Forest clearing and regional landsliding, Geology., 28, 311, doi:10.1130/0091-7613(2000)28<311:FCARL>2.0.CO;2, 2000.

Nadim, F., Kjekstad, O., Peduzzi, P., Herold, C., and Jaedicke, C.: Global landslide and avalanche hotspots, Landslides., 3, 159-173, doi:10.1007/s10346-006-0036-1, 2006.

Nicu, I. C. and Asăndulesei, A.: GIS-based evaluation of diagnostic areas in landslide susceptibility analysis of Bahluieț River Basin (Moldavian Plateau, NE Romania). Are Neolithic sites in danger?, Geomorphology., 314, 27-41, doi:10.1016/j.geomorph.2018.04.010, 2018.

Petley, D.: Global patterns of loss of life from landslides, Geology., 40, 927-930, doi:10.1130/g33217.1, 2012.

Pourghasemi, H. R. and Kerle, N.: Random forests and evidential belief function-based landslide susceptibility assessment in Western Mazandaran Province, Iran, Environmental Earth Sciences., 75, 185.181-185.117, doi:10.1007/s12665-015-4950-1, 2016.

Pradhan, B.: Remote sensing and GIS-based landslide hazard analysis and cross-validation using multivariate logistic regression model on three test areas in Malaysia, Advances in Space Research., 45, 1244-1256, doi:10.1016/j.asr.2010.01.006, 2010.

Qin, Y. and Liu, L.: Quantitative 3D Association of Geological Factors and Geophysical Fields with Mineralization and Its Significance for Ore Prediction: An Example from Anqing Orefield, China, Minerals., 8, 300, doi:10.3390/min8070300, 2018.

Reichenbach, P., Busca, C., Mondini, A. C., and Rossi, M.: The Influence of Land Use Change on Landslide Susceptibility Zonation: The Briga Catchment Test Site (Messina, Italy), Environmental Management., 54, 1372-1384, doi:10.1007/s00267-014-0357-0, 2014.

Reichenbach, P., Rossi, M., Malamud, B. D., Mihir, M., and Guzzetti, F.: A review of statistically-based landslide susceptibility models, Earth-Science Reviews., 180, 60-91, doi:10.1016/j.earscirev.2018.03.001, 2018.

Remondo, J., González, A., De Terán, J. R. D., Cendrero, A., Fabbri, A., and Chung, C. J. F.: Validation of landslide susceptibility maps; Examples and applications from a case study in northern Spain, Natural Hazards., 30, 437-449, doi:DOI 10.1023/B:NHAZ.0000007201.80743.fc, 2003.

Ruff, M. and Czurda, K.: Landslide susceptibility analysis with a heuristic approach in the Eastern Alps (Vorarlberg, Austria), Geomorphology., 94, 314-324, doi:10.1016/j.geomorph.2006.10.032, 2008.

Sameen, M. I., Pradhan, B., and Lee, S.: Application of convolutional neural networks featuring Bayesian optimization for landslide susceptibility assessment, Catena., 186, doi:10.1016/j.catena.2019.104249, 2020.

Smets, B., Delvaux, D., Ross, K. A., Poppe, S., Kervyn, M., d'Oreye, N., and Kervyn, F.: The role of inherited crustal structures and magmatism in the development of rift segments: Insights from the Kivu basin, western branch of the East African Rift, Tectonophysics., 683, 62-76, doi:10.1016/j.tecto.2016.06.022, 2016. 
Tien Bui, D., Pradhan, B., Lofman, O., and Revhaug, I.: Landslide Susceptibility Assessment in Vietnam Using Support Vector Machines, Decision Tree, and Naïve Bayes Models, Mathematical Problems in Engineering., 2012, 1-26, doi:10.1155/2012/974638, 2012.

Wang, H.B., Liu, G. J., Xu, W. Y., and Wang, G. H.: GIS-based landslide hazard assessment: an overview, Prog Phys Geog., 29, 548-567, doi:10.1191/0309133305pp462ra, 2005.

Waske, B., van der Linden, S., Oldenburg, C., Jakimow, B., Rabe, A., and Hostert, P.: imageRF - A user-oriented implementation for remote sensing image analysis with Random Forests, Environmental Modelling \& Software., 35, 192-193, doi:10.1016/j.envsoft.2012.01.014, 2012.

Wasowski, J., Bovenga, F., Nutricato, R., Nitti, D. O., and Chiaradia, M. T.: Applications Of Medium C-Band And High Resolution X-Band Multitemporal Interferometry In Landslide Investigations, ISPRS International Archives of the Photogrammetry, Remote Sensing and Spatial Information Sciences., XL-1-W5, 737-743, doi:10.5194/isprsarchives-XL-1-W5-737-2015, 2015.

Wu, W. C. and Ai, G.: Risk assessment of natural disasters in the course of selection of nuclear waste disposal (in Chinese with English abstract), Journal of East China Geological Institute., 18, 260-265, 1995.

Wu, W. C., De Pauw, E., and Hellden, U.: Assessing woody biomass in African tropical savannahs by multiscale remote sensing, International Journal of Remote Sensing., 34, 4525-4549, doi:10.1080/01431161.2013.777487, 2013.

Wu, W. C., Zucca, C., Karam, F., and Liu, G.: Enhancing the performance of regional land cover mapping, International Journal of Applied Earth Observation and Geoinformation., 52, 422-432, doi:10.1016/j.jag.2016.07.014, 2016.

Wu, W. C., Zucca, C., Muhaimeed, A. S., Al-Shafie, W. M., Fadhil Al-Quraishi, A. M., Nangia, V., Zhu, M., and Liu, G.: Soil salinity prediction and mapping by machine learning regression in Central Mesopotamia, Iraq, Land Degradation \& Development., 29, 4005-4014, doi:10.1002/ldr.3148, 2018.

Wu, W. C.: Application de la géomatique au suivi de la dynamique environnementale en zones arides, Ph.D. Université de Paris 1-Panthéon-Sorbonne, Paris, France, 2003.

Yilmaz, I.: Landslide susceptibility mapping using frequency ratio, logistic regression, artificial neural networks and their comparison: A case study from Kat landslides (Tokat-Turkey), Computers \& Geosciences., 35, 1125-1138, doi:10.1016/j.cageo.2008.08.007, 2009.

Youssef, A. M., Maerz, N. H., and Hassan, A. M.: Remote sensing applications to geological problems in Egypt: case study, slope instability investigation, Sharm El-Sheikh/Ras-Nasrani Area, Southern Sinai, Landslides., 6, 353-360, doi:10.1007/s10346-009-0158-3, 2009.

Zhang, K., Wu, X., Niu, R., Yang, K., and Zhao, L.: The assessment of landslide susceptibility mapping using random forest and decision tree methods in the Three Gorges Reservoir area, China, Environmental Earth Sciences., 76, doi:10.1007/s12665-017-6731-5, 2017.

Zhu, A. X., Miao, Y., Liu, J., Bai, S., Zeng, C., Ma, T., and Hong, H.: A similarity-based approach to sampling absence data for landslide susceptibility mapping using data-driven methods, Catena., 183, doi:10.1016/j.catena.2019.104188, 2019. 